\title{
Trend in the atmospheric heat source over the central and eastern Tibetan Plateau during recent decades: Comparison of observations and reanalysis data
}

\author{
WANG MeiRong ${ }^{1,2}$, ZHOU ShunWu $^{1} \&$ DUAN AnMin ${ }^{2 *}$ \\ ${ }^{1}$ Nanjing University of Information Science \& Technology, Nanjing 210044, China; \\ ${ }^{2}$ Institute of Atmospheric Physics, Chinese Academy of Sciences, Beijing 100029, China
}

Received July 19, 2011; accepted September 26, 2011; published online November 19, 2011

\begin{abstract}
The trend in the atmospheric heat source over the central and eastern Tibetan Plateau (CE-TP) is quantitatively estimated using historical observations at 71 meteorological stations, three reanalysis datasets from 1980-2008, and two satellite radiation datasets from 1984-2007. Results show that a weakening of sensible heat (SH) flux over the CE-TP continues. The most significant trend occurs in spring, induced mainly by decelerated surface wind speeds. The ground-air temperature difference shows a notable increasing trend over the last 5 years. Trends in net radiation flux of the atmospheric column over the CE-TP, evaluated by two satellite radiation datasets, are clearly different. Trends in the atmospheric heat source calculated by the three reanalysis datasets are not completely consistent, and even show opposite signals. Results from the two datasets both show a weakening of the heat source but the magnitude of one is significantly stronger, whereas an increase is indicated by the other data. Therefore, it is challenging to accurately calculate the trend in the atmospheric heat source over the CE-TP, particularly from the estimates of the reanalysis datasets.
\end{abstract}

Tibetan Plateau, atmospheric heat source, sensible heating, trend, station observation data, reanalysis datasets

Citation: Wang M R, Zhou S W, Duan A M. Trend in the atmospheric heat source over the central and eastern Tibetan Plateau during recent decades: Comparison of observations and reanalysis data. Chin Sci Bull, 2012, 57: 548-557, doi: 10.1007/s11434-011-4838-8

The Tibetan Plateau (TP) is situated on the subtropical eastcentral Eurasian continent. It is the highest (average elevation $>4000 \mathrm{~m}$ ) plateau in the world, with complex topography and surface conditions. As a strong heat source, the plateau directly heats the middle troposphere [1-3]. In spring, sensible heat $(\mathrm{SH})$ dominates the atmospheric heat source over the TP and works efficiently as a huge air pump [4], for not only the onset and maintenance of the Asian summer monsoon [5], but also for the development of weather systems over east China [6] and even the boreal summer climate pattern [6,7]. Changes in the thermal condition of the TP and the atmospheric circulation in East Asia are closely related [8]. Zhao and Chen [9] investigated the atmospheric heat source over the TP and its relationship with

*Corresponding author (email: anminduan@gmail.com) rainfall in China, and concluded that this heat source in spring may be regarded as a good indicator of a summer precipitation anomaly in east China. They also showed that it had a clear positive correlation with summer precipitation in the middle and lower reaches of the Yangtze River. Bai et al. [10] confirmed these results. Duan and $\mathrm{Wu}[11]$ pointed out that it is not adequate to study the influence of TP thermal forcing on the climate with an area-averaged heating index, because of the large area and various climate types of the TP.

Under a global warming scenario, TP warming is powerful, and the warming trend is much greater than surrounding regions at the same latitudes [12-15]. The thermal condition of the TP is an important influence on atmospheric circulation, climate change and long-term weather processes. The relationship between TP heating and variability 
of Asian monsoon systems is an especially important scientific topic. Previous work on the TP atmospheric heat source $[16,17]$ has been limited to seasonal and inter-annual scales; decadal-scale studies are rare. Recent studies [18,19] indicate that the TP heat source continues to weaken, and the weakening trend in $\mathrm{SH}$ over the plateau is greatest in spring. This was shown to be caused mainly by decelerated surface wind speeds, and was closely tied to a large-scale circulation shift produced by global warming. Given a lack of observation data over the TP, many researchers [20-25] calculated the atmospheric heat source from reanalysis data. For example, based on the reanalysis data, Zhu et al. [25] estimated the atmospheric heat source trend over the TP by a reverse computation method. Their results indicate that this heat source has persistently decreased in spring and summer during recent years, but snow depth in winter and spring increased.

There is great uncertainly in current reanalysis datasets over the TP. The reliability of trends in the TP heat source estimated by such datasets needs verification by observation data and trends calculated by different datasets should be quantitatively compared. This work quantitatively compares trends in the atmospheric heat source over the CE-TP from 1980 to 2008, using the reanalysis datasets and observations. The intent is to verify the applicability of those datasets for calculating the TP heat source.

\section{Data and methods}

\subsection{Data}

(i) The data in this study include the following sources: Regular surface meteorological observations with an initial quality control provided by the China Meteorological Administration (CMA). Data were gathered four times daily (0200, 0800, 1400, and 2000 Beijing time (BJT)) during 1980-2008, variables include surface air temperature $\left(T_{\mathrm{a}}\right)$, ground surface temperature $\left(T_{\mathrm{s}}\right)$, wind speed at $10 \mathrm{~m}$ above the surface $\left(V_{0}\right)$, and daily accumulated precipitation $\left(P_{\mathrm{r}}\right)$.

(ii) ISCCP (International Satellite Cloud Climatology Project, http://isccp.giss.nasa.gov/projects/flux.html) and GEWEX-SRB (Global Energy and Water Cycle ExperimentSurface Radiation Budget, http://eosweb.larc.nasa.gov/PRODOCS/srb/table_srb.html) satellite radiation datasets. Radiation fluxes include the downward and upward shortwave and long-wave fluxes at the top of the atmosphere and at the surface. Both datasets are from 1984 to 2007, with horizontal resolution $2.5^{\circ} \times 2.5^{\circ}$ and $1^{\circ} \times 1^{\circ}$.

(iii) NCEP/NCAR (National Centers for Environmental Prediction and National Center for Atmospheric Research for reanalysis datasets 1, http://www.esrl.noaa.gov/psd/data/ gridded/data.ncep.reanalysis.html); NCEP-DOE (NCEP and the Department of Energy for reanalysis datasets 2, http:// www.esrl.noaa.gov/psd/data/gridded/data.ncep.reanalysis2. html); and JRA-25 (Japan Meteorological Agency and Cen- tral Research Institute of Electric Power Industry co-production, http://jra.kishou.go.jp/JRA-25/index_en.html) global atmospheric reanalysis datasets, from 1980 to 2008. The numerical prediction models, assimilation programs, observing systems from NCEP-DOE are almost the same as NCEP/NCAR, but some errors in the latter are corrected, a simple rainfall assimilation over land surfaces is added, and some physical processes and parameterization schemes in the models are modified. These improvements are primarily reflected in surface temperature, radiation flux, surface water balance and other surface fluxes. In particular, the rainfall data assimilation significantly improved model simulation of soil moisture [26]. Therefore, the NCEP-DOE reanalysis dataset may be considered an updated version of NCEP/NCAR [26-28]. The horizontal resolutions in both NCEP/NCAR and NCEP-DOE are $2.5^{\circ} \times 2.5^{\circ}$, and $1.25^{\circ} \times$ $1.25^{\circ}$ in JRA-25.

The locations and altitudes of the 71 stations on the CE$\mathrm{TP}$ are shown in Figure 1. Most are in the Qinghai and $\mathrm{Xi}$ zang (Tibet) areas of China, and a few are in adjacent areas of Gansu, Sichuan, and Yunnan provinces. On the broad western plateau, only three stations are available and therefore they cannot fully represent that area. Therefore, we focus on the change of the atmospheric heat source over the CE-TP $\left(28^{\circ}-38^{\circ} \mathrm{N}, 85^{\circ}-105^{\circ} \mathrm{E}\right)$.

\subsection{Methods}

An atmospheric heat source (sink) is a physical quantity reflecting the heat budget of an air column [3]. For a given region, it is defined by that air column gaining (losing) heat over time. It can be expressed as

$$
\mathrm{E}=\mathrm{SH}+\mathrm{LH}+\mathrm{RC},
$$

where SH represents the local surface sensible heat transfer, $\mathrm{LH}$ is the latent heat released to the atmosphere by precipitation, and $\mathrm{RC}$ is the net radiation flux of the air column.

For calculation of $\mathrm{SH}$, the bulk aerodynamic method now is widely used:

$$
\mathrm{SH}=C_{\mathrm{p}} \rho C_{\mathrm{DH}} V_{0}\left(T_{\mathrm{s}}-T_{\mathrm{a}}\right),
$$

where $C_{\mathrm{p}}=1005 \mathrm{~J} \mathrm{~kg}^{-1} \mathrm{~K}^{-1}$ is the specific heat of dry air at constant pressure, $\rho$ is air density that decreases exponentially with elevation, $C_{\mathrm{DH}}$ is the (dimensionless) drag coefficient for heat, and $V_{0}$ is the mean wind speed measured at $10 \mathrm{~m}$ above ground. For a fixed location, changes in $\rho$ and $C_{\mathrm{DH}}$ should be small, and their impacts on $\mathrm{SH}$ are negligible. Therefore, the wind speed $V_{0}$ and ground-air temperature difference $\left(T_{\mathrm{s}}-T_{\mathrm{a}}\right)$ are the two key effects on $\mathrm{SH}$. Here, we assume $\rho=0.8 \mathrm{~kg} \mathrm{~m}^{-3}$ [3]. For the drag coefficient selection, Yeh et al. [3] proposed a value of $8 \times 10^{-3}$, but many studies [29-31] have shown that a mean value $C_{\mathrm{DH}}=4 \times 10^{-3}$ is more reasonable for the CE-TP. Li et al. [31,32] calculated drag coefficients on the eastern and western plateau, finding a $C_{\mathrm{DH}}$ 

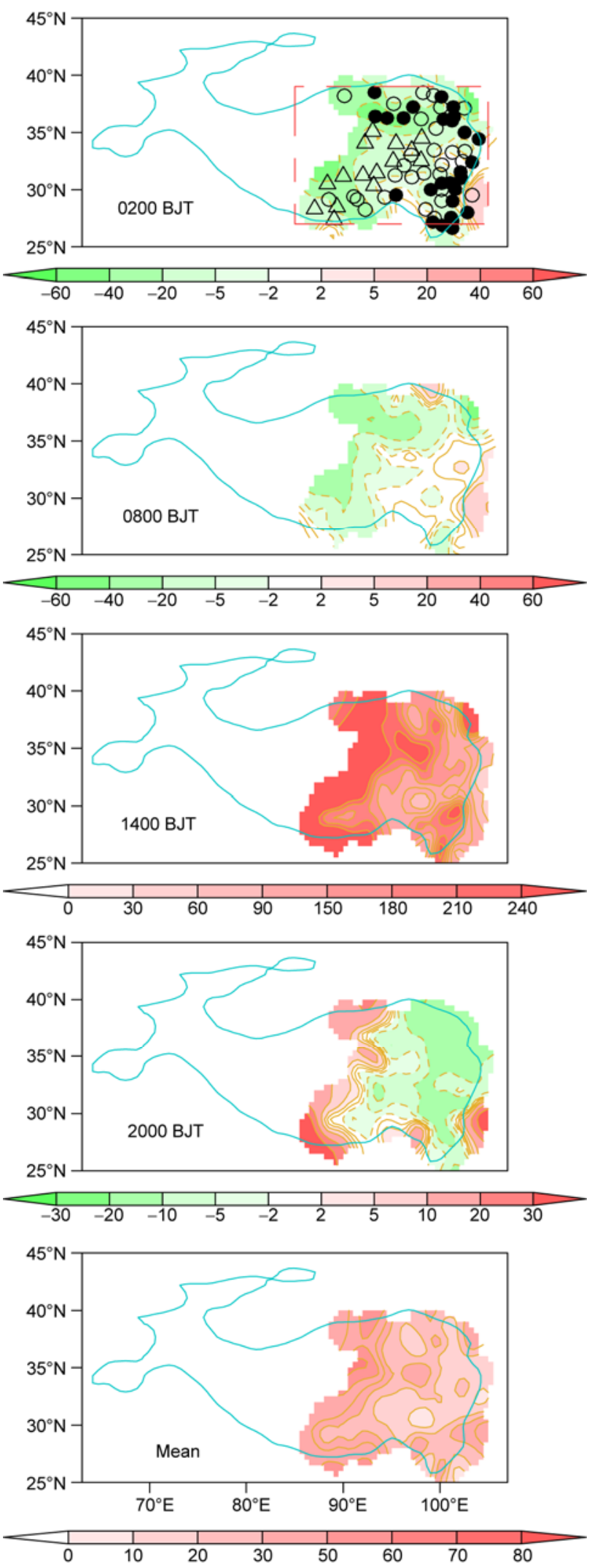

Figure 1 Annual mean SH flux ( $\mathrm{W} \mathrm{m}^{-2}$ ) over the CE-TP from 1980-2008. Triangles, open circles, and solid circles in the top panel denote stations at or higher than 4000, 3000, and $2000 \mathrm{~m}$, respectively. Thick curve outlines the TP area with average altitude higher than $2500 \mathrm{~m}$, and dashed box denotes the CE-TP area. range from $3.3 \times 10^{-3}$ to $4.4 \times 10^{-3}$ on the eastern plateau, we therefore selected an average value of $4 \times 10^{-3}$.

LH can be calculated from the precipitation via the following:

$$
\mathrm{LH}=P_{\mathrm{r}} \times L_{\mathrm{w}} \times \rho,
$$

where $L_{\mathrm{w}}=2.5 \times 10^{6} \mathrm{~J} \mathrm{~kg}^{-1}$ is the condensation heat coefficient.

$$
\begin{aligned}
\mathrm{RC} & =R_{\infty}-R_{0} \\
& =\left(S_{\infty}^{\downarrow}-S_{\infty}^{\uparrow}\right)-\left(S_{0}^{\downarrow}-S_{0}^{\uparrow}\right)-\left(F_{0}^{\downarrow}-F_{0}^{\uparrow}\right)-F_{\infty},
\end{aligned}
$$

where $R_{\infty}$ and $R_{0}$ are the net radiation values at the top of the atmosphere and at the earth surface, respectively. Variables $S$ and $F$ denote shortwave and long-wave radiation fluxes, subscripts $\infty$ and 0 denote the top of the atmosphere and the surface, and superscripts $\downarrow$ and $\uparrow$ represent downward and upward transports.

The apparent heat source $Q_{1}$ can be computed by the following [33]:

$$
c_{p}\left[\frac{\partial T}{\partial t}+\vec{V} \cdot \nabla T+\left(\frac{p}{p_{0}}\right)^{k} \omega \frac{\partial \theta}{\partial p}\right]=Q_{1} .
$$

The above equation can be integrated vertically:

$$
\left\langle Q_{1}\right\rangle=\frac{1}{g} \int_{100}^{p_{0}} Q_{1} d p \approx L P+Q_{\mathrm{S}}+\left\langle Q_{\mathrm{R}}\right\rangle,
$$

where $T$ is temperature, $\vec{V}$ is the horizontal wind vector, $p$ is pressure, $p_{0}=1000 \mathrm{hPa}$, and $k=R / c_{p} ; R$ and $c_{p}$ denote the gas constant and specific heat of dry air at constant pressure, respectively. $\omega$ is the vertical $p$ velocity, $\theta$ is potential temperature, $L$ is the latent heat of condensation, $P$ is precipitation rate, $Q_{\mathrm{S}}$ is the surface sensible heat, and $\left\langle Q_{\mathrm{R}}\right\rangle$ represents the vertical integration of radiation heating (cooling).

The linear trend was calculated by the least-squares method and the $t$-test was used to determine the confidence level.

\section{Climatology of the atmospheric heat source/ sink over the CE-TP}

Figure 1 shows the annual mean SH over the CE-TP during 1980-2008. Most stations had negative SH at night (0200 and $0800 \mathrm{BJT}$ ), which indicates a downward $\mathrm{SH}$ transfer from air to the land surface. The SH at $0200 \mathrm{BJT}$ was the minimum. At $1400 \mathrm{BJT}$, a strongly positive SH was widespread on the CE-TP, consistent with Duan and $\mathrm{Wu}$ [18]. The annual mean of the 71-station-averaged $\mathrm{SH}$ was approximately $40 \mathrm{~W} \mathrm{~m}^{-2}$, about half that given by Yeh et al. [3], and $15 \mathrm{~W} \mathrm{~m}^{-2}$ smaller than in Yang et al. [19]. However, our value agrees well with Chen et al. [17]. 
A principal feature of the plateau climate is a strong summer monsoon, and the magnitude of LH in JJA (JuneJuly-August) was much greater than at other times of the year. During the rainy season, $\mathrm{LH}$ over most areas typically exceeds $80 \mathrm{~W} \mathrm{~m}^{-2}$, overwhelming $\mathrm{SH}$ or RC over the CETP (figure not shown). The RC was calculated by ISCCP and SRB satellite radiation datasets. Combined with the 71-station-average $\mathrm{SH}$ and $\mathrm{LH}$, we obtained the atmospheric heat source over the CE-TP (OBS1 and OBS2) (Table 1). The results show that the TP is a heat source in MAM (March-April-May) and JJA, but a heat sink in SON (September-October-November) and DJF (December-JanuaryFebruary). Most contributions to the total diabatic heating came from SH in MAM and from LH in JJA, which was usually more than double the $\mathrm{SH}$ in that season. On the other hand, $\mathrm{RC}$ ranged from -50 to $-100 \mathrm{~W} \mathrm{~m}^{-2}$, and differences between the seasonal averages calculated by ISCCP and SRB were very small, and especially so for annual averages. In addition, the averages were all negative, tending to cool the air column. These results agree qualitatively with previous studies $[3,17]$.

\section{Trend in SH over the CE-TP}

\subsection{Trend in $\mathrm{SH}$ at different times of the day}

On average, $\mathrm{SH}$ reaches its daily maximum and minimum in the afternoon and night, respectively [3,18]. Figure 2 shows time sequences over the CE-TP of $T_{\mathrm{a}}, T_{\mathrm{s}},\left(T_{\mathrm{s}}-T_{\mathrm{a}}\right), V_{0}$, and $\mathrm{SH}$, at 0200, 0800, 1400, and 2000 BJT. At 0200 BJT, $T_{\mathrm{a}}$ increased rapidly, and reached a peak in 2006. The linear variation trend (LVT) from $1980-2008$ was $0.39^{\circ} \mathrm{C} / 10 \mathrm{a}$; however, it had a slight downward trend during the last 5 years (dotted line), at $-0.21^{\circ} \mathrm{C} / 10 \mathrm{a}$. Over the same period, $T_{\mathrm{s}}$ had similar inter-annual variations and decadal trend as $T_{\mathrm{a}}$, and its LVT was $0.56^{\circ} \mathrm{C} / 10 \mathrm{a}$. This means that $T_{\mathrm{s}}$ rose faster than $T_{\mathrm{a}}$, resulting in a $\left(T_{\mathrm{s}}-T_{\mathrm{a}}\right)$ increase of $0.17^{\circ} \mathrm{C} / 10 \mathrm{a}$. The rise was especially pronounced from 2004-2008. Duan and

Table 1 Climatology (1984-2007) of atmospheric heat source/sink and each component over CE-TP (Unit: W m $\left.{ }^{-2}\right)$

\begin{tabular}{lccccc}
\hline Component & MAM & JJA & SON & DJF & 29 \\
SH & 61 & 41 & 27 & 37 & 4 \\
LH & 29 & 98 & -70 & $-71 /-94$ \\
RC (ISCCP/SRB) & $-52 /-61$ & $-74 /-56$ & $-71 /-91$ & $-38 /-61$ \\
OBS1/OBS2 & $38 / 29$ & $65 / 83$ & $-17 /-27$ & $12 / 6$ & \\
\hline
\end{tabular}
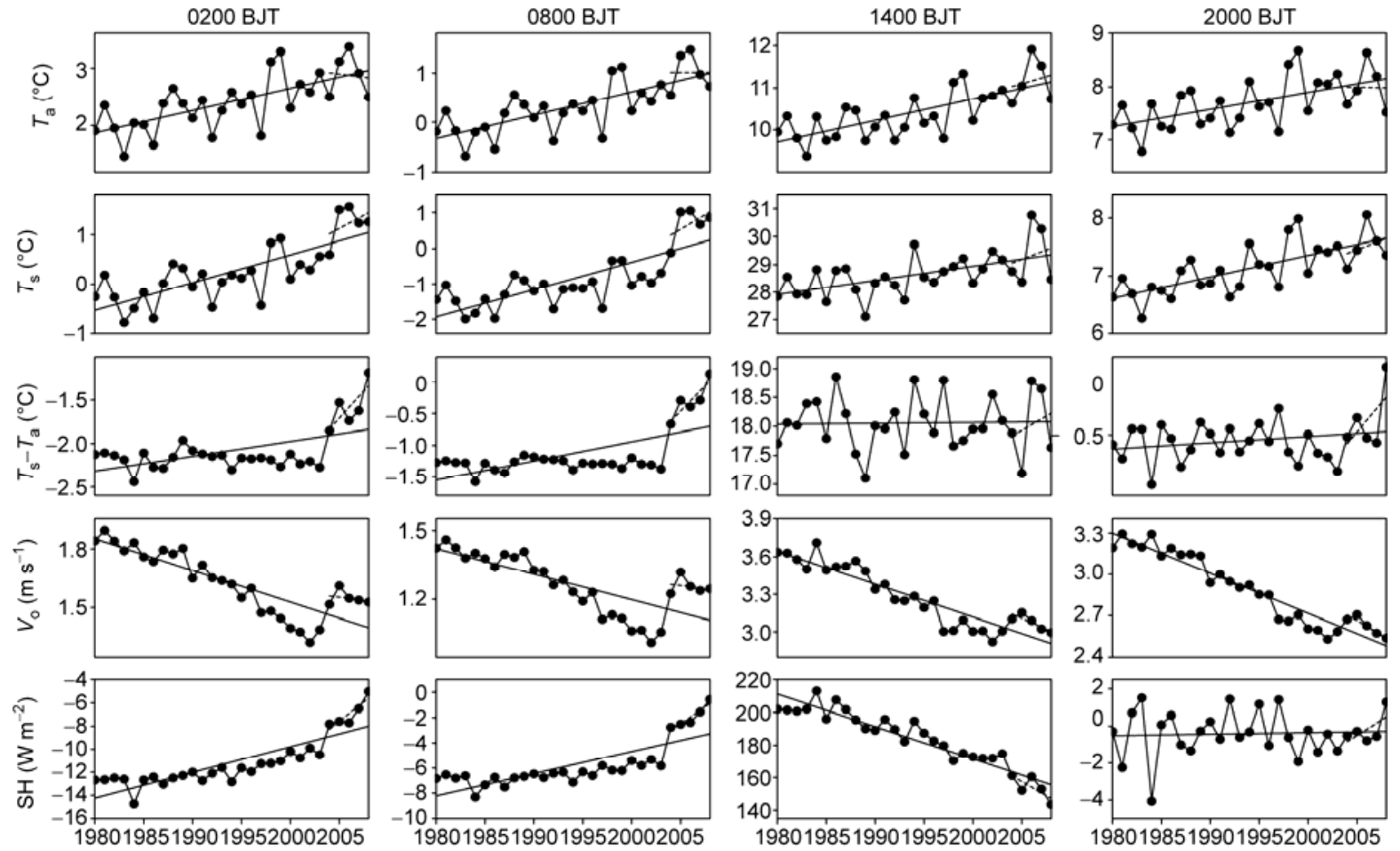
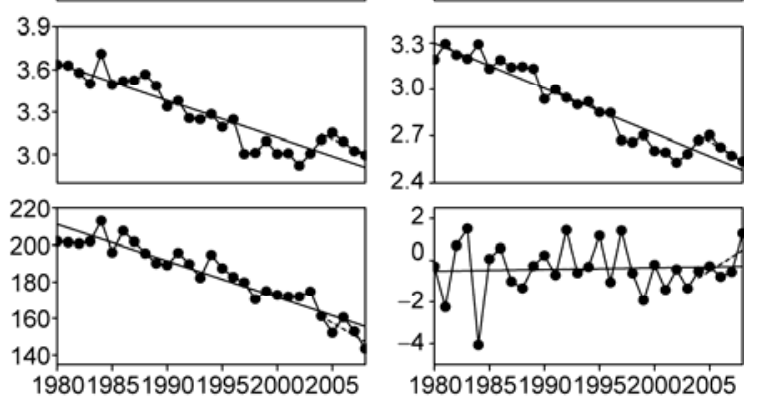

Figure 2 Temporal evolution of several variables over the CE-TP at 0200, 0800, 1400 and 2000 BJT. Dotted lines represent trends in each variable during the last 5 years. 
Wu [18] suggested that $\left(T_{\mathrm{s}}-T_{\mathrm{a}}\right)$ had a downward trend from 1980-2003, which is different the results here. The weakening trend in $V_{0}$ continued, with a LVT of $-0.16\left(\mathrm{~m} \mathrm{~s}^{-1}\right) /$ 10a, while $\mathrm{SH}$ increased at $2.23\left(\mathrm{~W} \mathrm{~m}^{-2}\right) / 10 \mathrm{a}$.

The trends in $T_{\mathrm{a}}, T_{\mathrm{s}}$ and $V_{0}$ at $14 \mathrm{BJT}$ are similar to those at $0200 \mathrm{BJT}$; their LVTs were $0.51{ }^{\circ} \mathrm{C} / 10 \mathrm{a}, 0.52^{\circ} \mathrm{C} / 10 \mathrm{a}$ and $-0.26\left(\mathrm{~m} \mathrm{~s}^{-1}\right) / 10 \mathrm{a}$, respectively, while $\left(T_{\mathrm{s}}-T_{\mathrm{a}}\right)$ had no obvious trend. The daily maximum SH usually occurred at noon, and the trend at this time declined remarkably $\left(-19.8\left(\mathrm{~W} \mathrm{~m}^{-2}\right) / 10 \mathrm{a}\right)$. As a consequence, the daily mean $\mathrm{SH}$ showed a clear decrease. Taking the time derivative of the bulk aerodynamic formula and comparing each item, it is easy to see that the trend of SH depended mainly on the change in $V_{0}$. Furthermore, the long-term decrease $V_{0}$, induced the weakening of $\mathrm{SH}$, especially during the last 5 years $\left(-34.6\left(\mathrm{~W} \mathrm{~m}^{-2}\right) / 10 \mathrm{a}\right)$. At 0800 BJT, SH displayed an upward trend (1.76 (W $\left.\left.\mathrm{m}^{-2}\right) / 10 \mathrm{a}\right)$, but there was no obvious trend at $2000 \mathrm{BJT}(0.08$ $\left.\left(\mathrm{W} \mathrm{m}^{-2}\right) / 10 \mathrm{a}\right)$. Thus, the long-term trend in $\mathrm{SH}$ over the CE-TP was increasing at night and decreasing at $1400 \mathrm{BJT}$. Except for the $\left(T_{\mathrm{s}}-T_{\mathrm{a}}\right)$ at 1400 and $2000 \mathrm{BJT}$, and $\mathrm{SH}$ at $2000 \mathrm{BJT}$, the LVTs in the remaining variables and times exceeded the $99 \%$ confidence level. At both 1400 and 2000 BJT, $\left(T_{\mathrm{s}}-T_{\mathrm{a}}\right)$ showed a clear trend over the last 5 years, and the LVT at 2000 BJT exceeded the $99 \%$ confidence level.

\subsection{Seasonal differences of the SH trend}

Figure 3 shows long-term trends in $\mathrm{SH}$ during the four sea- sons. Clearly, the annual minimum and maximum $\mathrm{SH}$ over the CE-TP occurred in DJF and MAM, respectively.

Both $T_{\mathrm{a}}$ and $T_{\mathrm{s}}$ increased significantly in DJF and MAM. In DJF, the increase in $T_{\mathrm{s}}\left(0.7^{\circ} \mathrm{C} / 10 \mathrm{a}\right)$ was faster than $T_{\mathrm{a}}$ $\left(0.58^{\circ} \mathrm{C} / 10 \mathrm{a}\right)$. In MAM, the increase in $T_{\mathrm{s}}\left(0.61^{\circ} \mathrm{C} / 10 \mathrm{a}\right)$ was also more rapid than $T_{\mathrm{a}}\left(0.43^{\circ} \mathrm{C} / 10 \mathrm{a}\right)$, which led to an increase in $\left(T_{\mathrm{s}}-T_{\mathrm{a}}\right)$ of $0.18^{\circ} \mathrm{C} / 10 \mathrm{a}$. On the other hand, $V_{0}$ decreased persistently in DJF $\left(-0.19\left(\mathrm{~m} \mathrm{~s}^{-1}\right) / 10 \mathrm{a}\right)$ and MAM $\left(-0.27\left(\mathrm{~m} \mathrm{~s}^{-1}\right) / 10 \mathrm{a}\right), \mathrm{SH}$ also showed a conspicuous weakening trend in DJF $\left(-2.2\left(\mathrm{~W} \mathrm{~m}^{-2}\right) / 10 \mathrm{a}\right)$ and MAM $(-5.8$ $\left.\left(\mathrm{W} \mathrm{m}{ }^{-2}\right) / 10 \mathrm{a}\right)$. For JJA and SON, $\left(T_{\mathrm{s}}-T_{\mathrm{a}}\right)$ increased, with LVTs of $0.09^{\circ} \mathrm{C} / 10 \mathrm{a}$ and $0.12^{\circ} \mathrm{C} / 10 \mathrm{a}$, indicating that $T_{\mathrm{s}}$ rose more rapidly than $T_{\mathrm{a}}$. In contrast, the LVTs of $V_{0}$ in JJA and SON were $-0.2\left(\mathrm{~m} \mathrm{~s}^{-1}\right) / 10 \mathrm{a}$ and $-0.16\left(\mathrm{~m} \mathrm{~s}^{-1}\right) / 10 \mathrm{a}$, respectively, and $\mathrm{SH}$ had a similar trend $\left(-4.4\left(\mathrm{~W} \mathrm{~m}^{-2}\right) / 10 \mathrm{a}\right.$ and $\left.-2.6\left(\mathrm{~W} \mathrm{~m}^{-2}\right) / 10 \mathrm{a}\right)$. Except for the LVT in $\left(T_{\mathrm{s}}-T_{\mathrm{a}}\right)$ exceeding $90 \%$ and $95 \%$ confidence levels in JJA and DJF, respectively, the LVTs for the remaining variables and seasons all exceeded the $99 \%$ confidence level.

Based on the Monin-Obukhov similarity theory and turbulence measurements, Yang et al. [34] developed a physical scheme to estimate daily mean SH flux from CMA station data (hereafter, the Yang scheme), and they computed recent trends in SH flux on the Tibetan Plateau [19]. The Yang scheme takes into account diurnal variations in heat transfer, and their weakening trend is smaller than we calculated. The trends are similar, however, and this does not affect the qualitative conclusion that the $\mathrm{SH}$ flux has shown
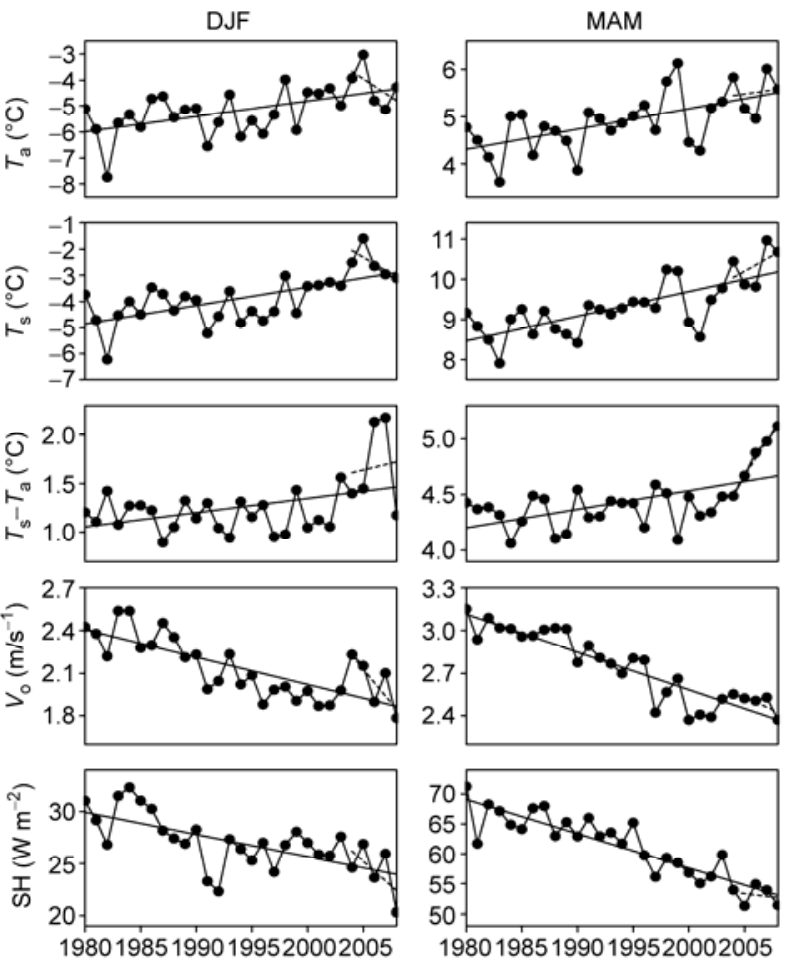
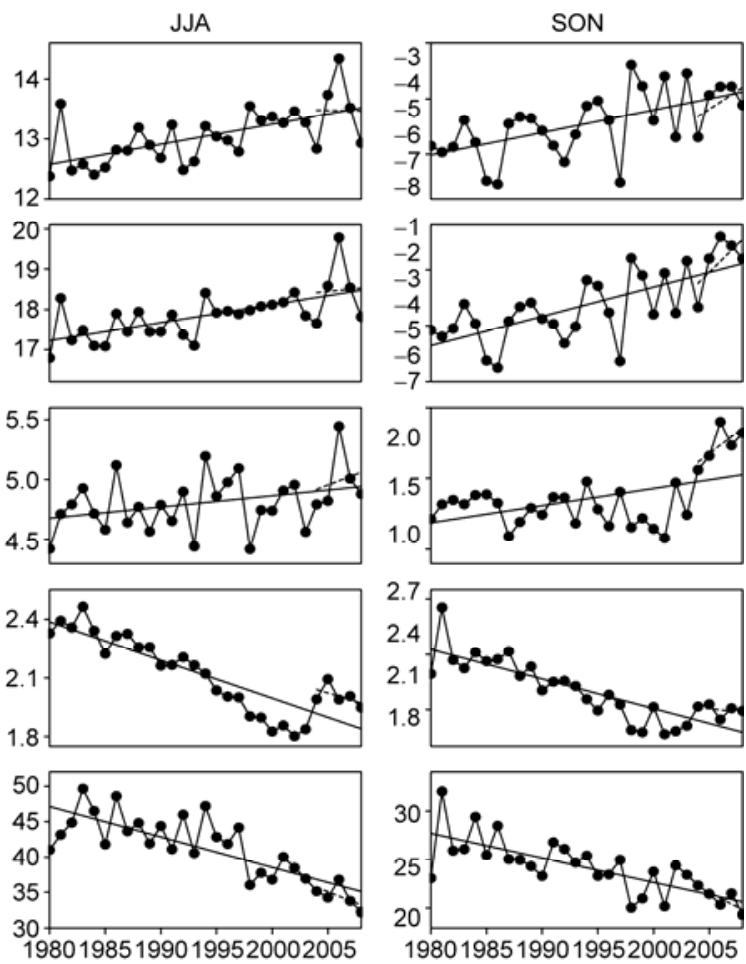

Figure 3 Same as in Figure 2, except for DJF, MAM, JJA and SON. 
a persistent weakening.

\subsection{Spatial distribution of the SH trend}

There are unique weather and climate features in the TP, because of its complex terrain. Figure 4 shows the spatial distribution of LVTs for annual $T_{\mathrm{a}}, V_{0}, T_{\mathrm{s}}$ and $\mathrm{SH}$ over the CE-TP, from 1980-2008. In contrast to increases in $T_{\mathrm{a}}$ and $T_{\mathrm{s}}$ across the study area, $V_{0}$ and $\mathrm{SH}$ clearly decreased in most areas. In fact, for $T_{\mathrm{a}}, V_{0}, T_{\mathrm{s}}$ and $\mathrm{SH}$, a significant trend (at the $95 \%$ level) was recorded by $65,54,59$, and 46 stations, respectively (total number of stations is 71). The stations represent different altitudes scatter at the CE-TP, which illustrates that the trends in all variables are not directly related to elevation. Changes in $T_{\mathrm{a}}, V_{0}$ and $T_{\mathrm{s}}$ were not linearly correlated with $\mathrm{SH}$, as reflected by its formula.

\section{Trends in LH and RC over the CE-TP}

\subsection{Trend in LH over the CE-TP}

In contrast to the SH decreased on the CE-TP, LH had a weak
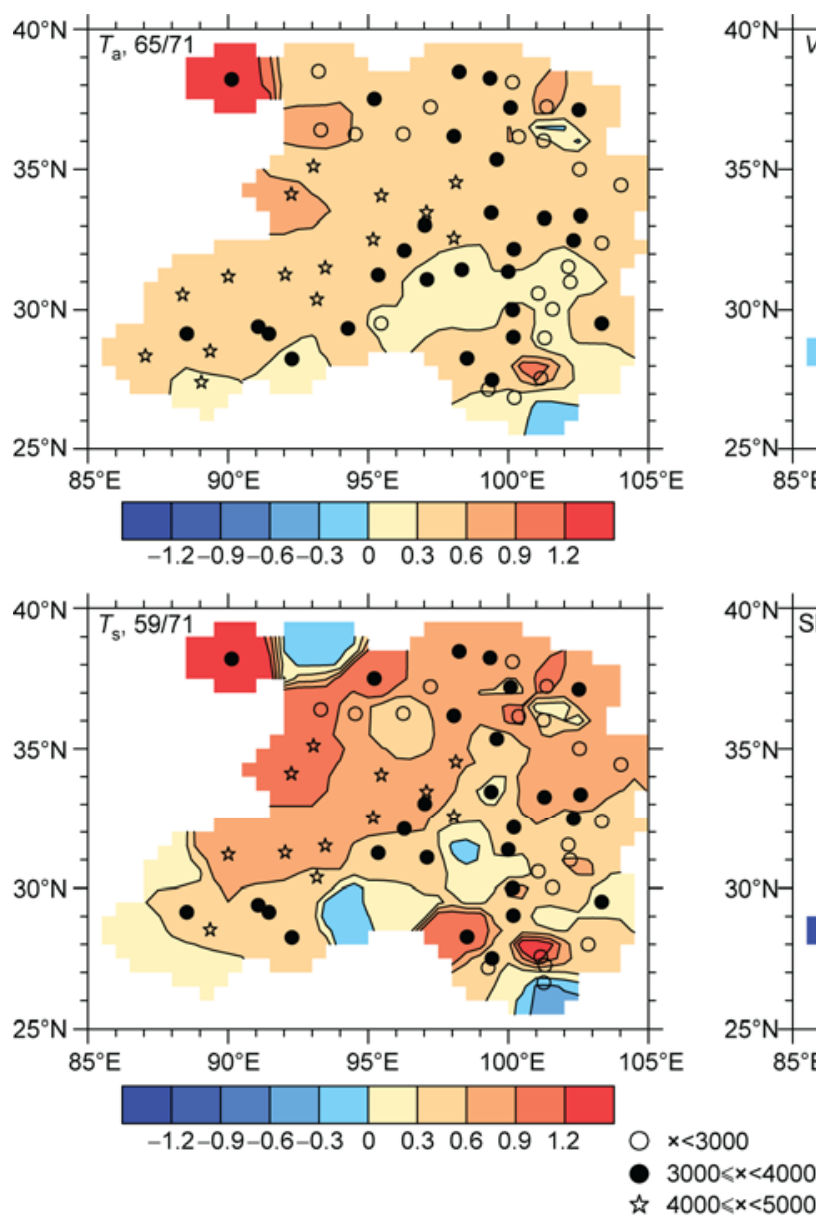

Figure 4 CE-TP spatial distribution of LVTs for annual means of $T_{\mathrm{a}}\left({ }^{\circ} \mathrm{C} / 10 \mathrm{a}\right), V_{0}\left(\left(\mathrm{~m} \mathrm{~s}^{-1}\right) / 10 \mathrm{a}\right), T_{\mathrm{s}}\left({ }^{\circ} \mathrm{C} / 10 \mathrm{a}\right)$, and $\mathrm{SH}\left(\left(\mathrm{W} \mathrm{m}^{-2}\right) / 10 \mathrm{a}\right)$ from 1980 to 2008 . Stations plotted in each panel have LVTs above $95 \%$ confidence level. Open dots, solid dots and stars denote stations at altitudes below $3000 \mathrm{~m}$, from 3000-4000 m, and from 4000-5000 m above sea level, respectively.

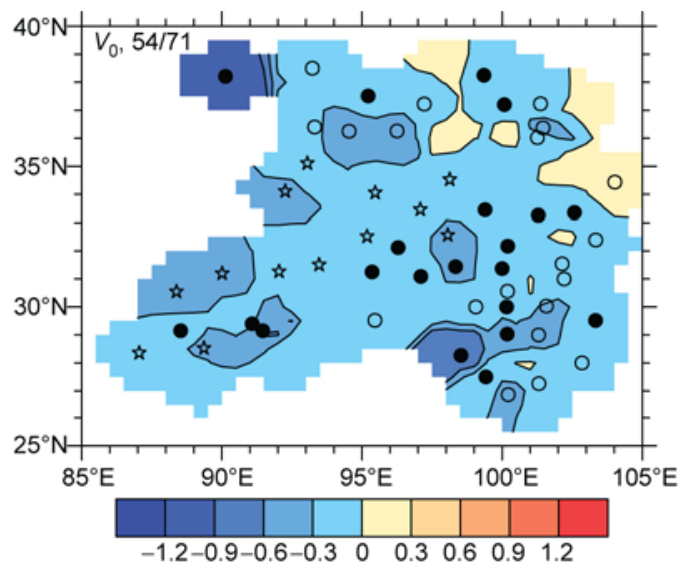

upward trend. Figure 5 shows the spatial distribution of LVTs for LH in four seasons during 1980-2008. LH is calculated from precipitation, so their spatial distributions are almost the same [35-36]. There was a widespread increase in MAM except at few stations, and the average LVT was 1.9 $\left(\mathrm{W} \mathrm{m}^{-2}\right) / 10 \mathrm{a}$ (Table 2 ). The spatial distribution was roughly a north-south reverse type, and the reduced precipitation in the north may reflect the strong westerlies and the desert climate [37]. However, LH became as important as $\mathrm{SH}$, even more important in JJA, and it formed a "sandwich" pattern, with an increase in the northern and southern CETP but a decrease in the middle. This pattern may be subject to changes in the plateau summer monsoon. The LH in SON decreased over a larger area. During DJF, precipitation was much less than the rest of the year, although it increased in some areas. Overall, LH increased across the region and its LVT was $0.5\left(\mathrm{~W} \mathrm{~m}^{-2}\right) / 10 \mathrm{a}$ (Table 2).

\subsection{Trend in RC over the CE-TP}

Previous work on RC was faced with many difficulties because of data constraints. The development of satellite data,

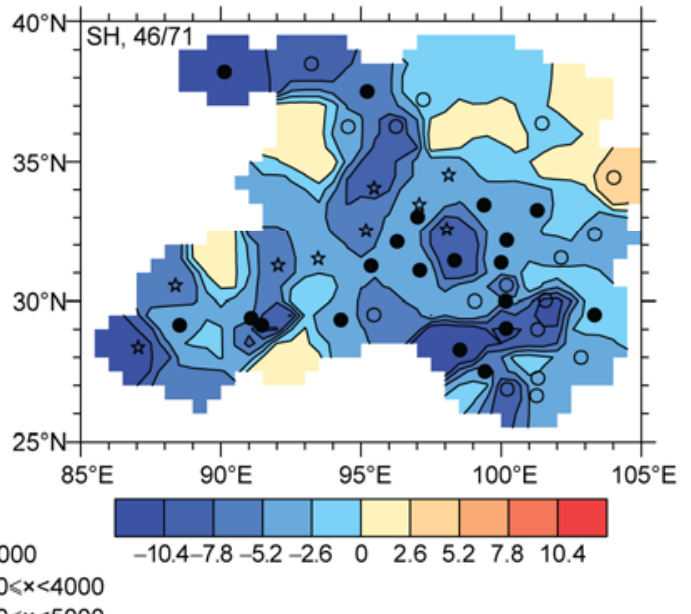



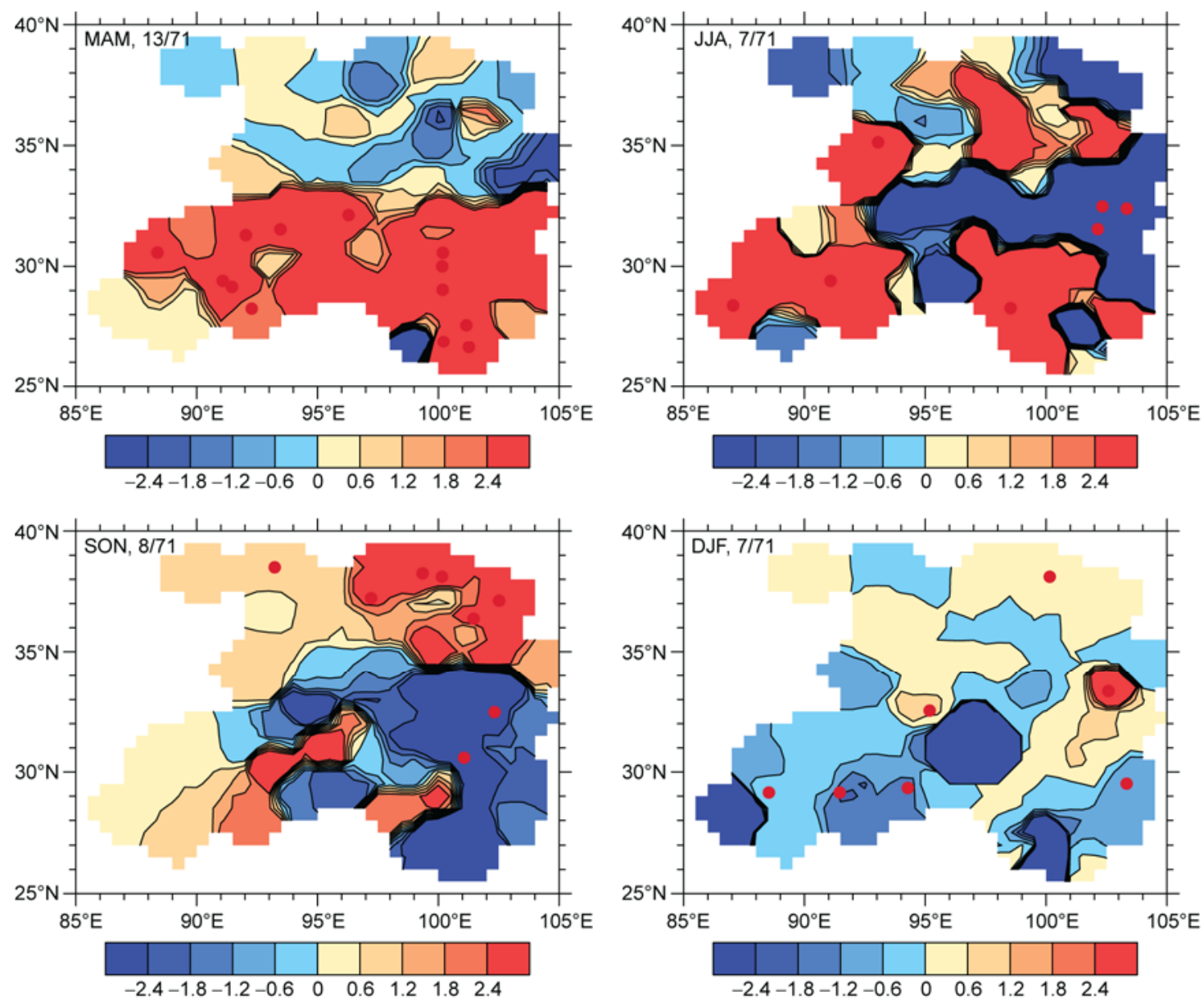

Figure 5 CE-TP spatial distribution of LVTs for LH $\left(\left(\mathrm{W} \mathrm{m}^{-2}\right) / 10 \mathrm{a}\right)$ in four seasons during 1980-2008. Stations with LVTs significant at the $95 \%$ level are plotted and their number (out of the total station number) is given at upper left of each panel.

Table 2 Trend in atmospheric heat source/sink and its components over the CE-TP (Unit: $\left.\left(\mathrm{W} \mathrm{m}^{-2}\right) / 10 \mathrm{a}\right)^{\mathrm{a}}$

\begin{tabular}{lccccc}
\hline Component & MAM & JJA & SON & DJF & Annual \\
\hline SH & -5.8 & -4.4 & -2.6 & -2.2 & -3.8 \\
LH & 1.9 & 0.5 & -0.5 & -0.1 & 0.5 \\
RC(ISCCP/SRB) & $-4.9 /-2.1$ & $-9.4 / 0.3$ & $-11.6 / 2.0$ & $-5.1 / 1.6$ & $-6.8 / 0.5$ \\
E & $-8.8 /-6$ & $-13.3 /-3.6$ & $-14.7 /-1.1$ & $-7.4 /-0.7$ & $-11.05 /-2.9$ \\
\hline
\end{tabular}

a) Analysis period for SH and LH is 1980-2008, and 1984-2007 for RC.

however, began to offer long, continuous and geographically extensive observations for more systematic and detailed RC study. Nevertheless, the applicability of satellite data and consistency between different satellite datasets are concerns. We therefore calculate and quantitatively compare the trend in RC over the CE-TP using the ISCCP and $\mathrm{SRB}$ radiation datasets.

Figure 6 illustrates the temporal evolution of annualmean radiation flux of the air column over the region, as computed from the aforementioned datasets of 1984-2007.

All net shortwave fluxes calculated with ISCCP and SRB data show increases, but of substantially different magni- tude $\left(2.3\left(\mathrm{~W} \mathrm{~m}^{-2}\right) / 10 \mathrm{a}\right.$ and $0.1\left(\mathrm{~W} \mathrm{~m}^{-2}\right) / 10 \mathrm{a}$, respectively). The net long-wave fluxes were very different and the signs of the LVTs were opposite. The LVTs of net long-wave flux and $\mathrm{RC}$ computed from ISCCP data were $-10.3\left(\mathrm{~W} \mathrm{~m}^{-2}\right) / 10 \mathrm{a}$ and $-8.0\left(\mathrm{~W} \mathrm{~m}^{-2}\right) / 10 \mathrm{a}$, respectively, whereas corresponding LVTs computed from SRB were $0.4\left(\mathrm{~W} \mathrm{~m}^{-2}\right) / 10 \mathrm{a}$ and 0.5 $\left(\mathrm{W} \mathrm{m} \mathrm{m}^{-2}\right) / 10 \mathrm{a}$, respectively. Further analysis showed that these differences were mainly caused by different surface longwave radiation cooling schemes (not shown). It is therefore evident that the use of satellite radiation data brings a great deal of uncertainty to RC calculation. Table 2 shows that $\mathrm{RC}$ contributes significantly to the total atmospheric heat 

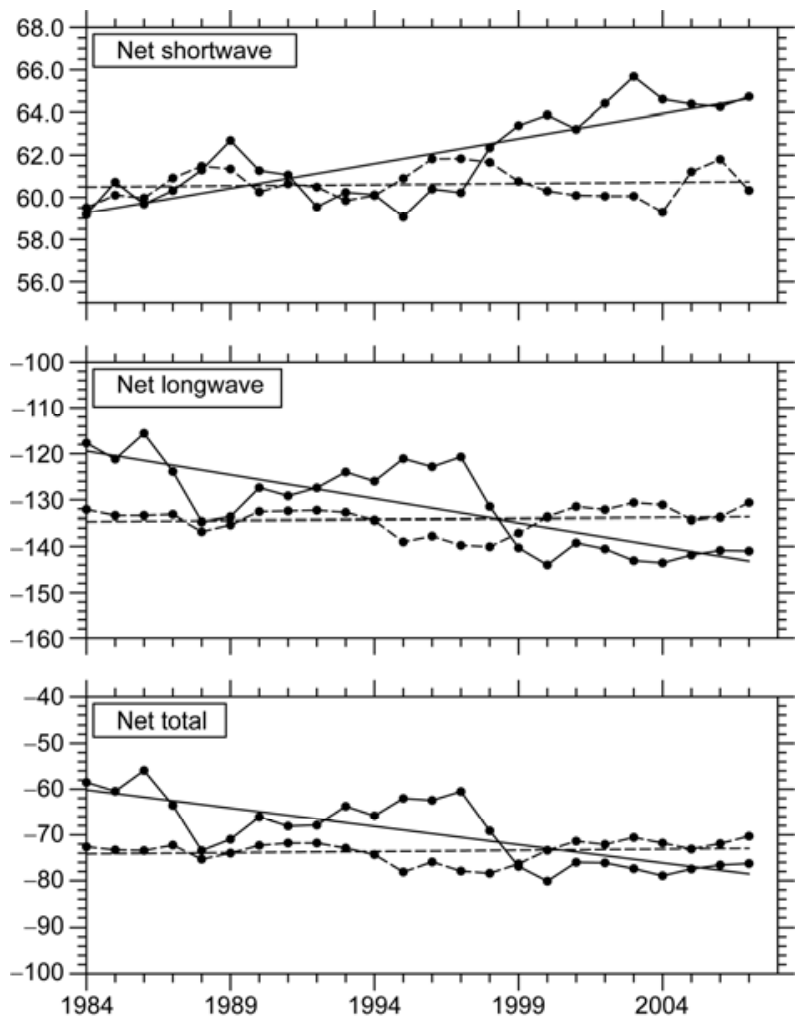

Figure 6 Temporal evolution of annual mean radiation flux $\left(\mathrm{W} \mathrm{m}^{-2}\right)$ of the air column over CE-TP, computed from ISCCP (solid line) and SRB (dotted line) datasets of 1984-2007.

source, so the trends in the atmospheric heat source over the CE-TP have some uncertainty.

\section{Comparison of trends in atmospheric heat source over the CE-TP calculated by observations and reanalysis datasets}

For a long time, studies of global atmospheric circulation, climate change, climate diagnostics etc. were based almost exclusively on observations. With the advent of NCEP/ NCAR, NCEP-DOE and JRA-25 reanalysis datasets, there has been tremendous progress, especially for the TP where there are sparse stations and relatively short records. The reanalysis data has good continuity and long time series, compensating for the lack of actual observations in the region. Many studies [38-40] have tried to verify the applicability of the reanalysis datasets to the TP, and suggest that although there are systematic biases in the datasets, they are still useful for climate research. Here, we compare results of the heat source calculated from three reanalysis datasets with OBS1 and OBS2, to test the applicability of the datasets. This may provide a reference for selection and use of the reanalysis data in future research.

Figure 7 shows that trends in the atmospheric heat source over the CE-TP calculated by NCEP/NCAR, NCAP-DOE,

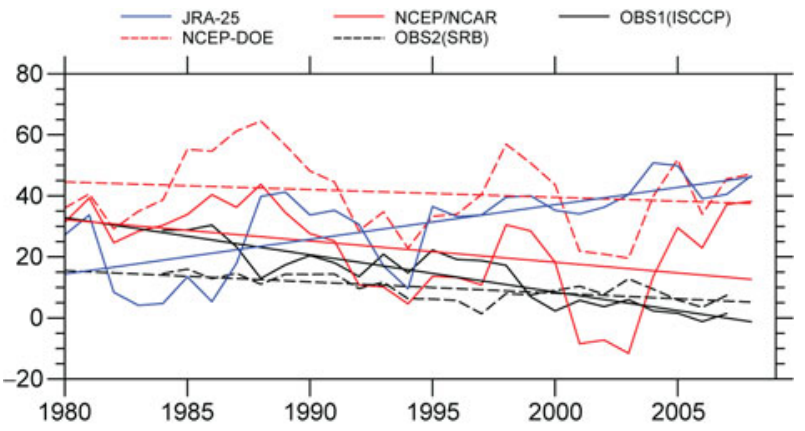

Figure 7 CE-TP temporal evolution of annual mean atmospheric heat source $\left(\mathrm{W} \mathrm{m}^{-2}\right)$, calculated from observations (1984-2007) and reanalysis datasets (1980-2008). Black solid line represents OBS1 (RC calculated from ISCCP) and black dotted line OBS2 (RC calculated from SRB). Red solid line, red dotted line and blue solid line represent NCEP/NCAR, NCEP-DOE, and JRA-25 data, respectively.

OBS1 and OBS2 were decreasing. For inter-annual variability characteristics and the long-term trend, the results of the two NCEP datasets were close to OBS1 $\left(-12.1\left(\mathrm{~W} \mathrm{~m}^{-2}\right) / 10 \mathrm{a}\right)$ and OBS2 $\left(-3.7\left(\mathrm{~W} \mathrm{~m}^{-2}\right) / 10 \mathrm{a}\right)$. The NCEP LVTs were -7.0 $\left(\mathrm{W} \mathrm{m}^{-2}\right) / 10 \mathrm{a}$ and $-2.5\left(\mathrm{~W} \mathrm{~m}^{-2}\right) / 10 \mathrm{a}$, whereas JRA-25 increased significantly $\left(11.3\left(\mathrm{~W} \mathrm{~m}^{-2}\right) / 10 \mathrm{a}\right)$. Furthermore, because of obvious differences in the trends from ISCCP and SRB, the LVTs of OBS1 and OBS2 had some gaps. Correlation coefficients between the heat sources calculated by observations and the reanalysis datasets are listed in Table 3. The observations span only 24 years (1984-2007), so we ensured the same period for calculating correlations. NCEPDOE is regarded as an upgraded version of the NCEP/NCAR, and this is borne out by the good correlation between them in Table 3, and their trends were also consistent with the observations. The JRA-25 was anti-correlated with OBS1 and OBS2, and correlation coefficients all exceeded the 95\% level. Using equation (5), further analysis indicated that $Q_{1}$ was clearly related with its vertical transport item $q_{13}\left(c_{p}\left(p / p_{0}\right)^{k} \omega \times \partial \theta / \partial p\right)$. In other words, the factor with the greatest contribution to $Q_{1}$ was $q_{13}$ [41].

Figure 8 shows the temporal evolution of $q_{13}$ and $\omega$ computed from NCEP-DOE and JRA-25 data (we only compared NCEP-DOE with JRA-25, because the levels of their variables are consistent). The LVTs $\left(0.4\left(\mathrm{~W} \mathrm{~m}^{-2}\right) / 10 \mathrm{a}\right.$ and $\left.9.8\left(\mathrm{~W} \mathrm{~m}^{-2}\right) / 10 \mathrm{a}\right)$ of $q_{13}$ from the two datasets were significantly different. Further analysis found that $q_{13}$ was affected

Table 3 Correlation coefficients between CE-TP heat sources, calculated from three reanalysis datasets (1980-2008) and OBS1, OBS2 (1984-2007)

\begin{tabular}{lcccc}
\hline \multicolumn{1}{c}{$E\left(<Q_{1}>\right)$} & OBS2 & NCEP/NCAR & NCEP-DOE & JRA-25 \\
\hline OBS1 & 0.49 & 0.34 & 0.32 & -0.73 \\
OBS2 & & 0.29 & 0.32 & -0.39 \\
NCEP/NCAR & & & 0.83 & -0.10 \\
NCEP-DOE & & & & 0.12 \\
\hline
\end{tabular}




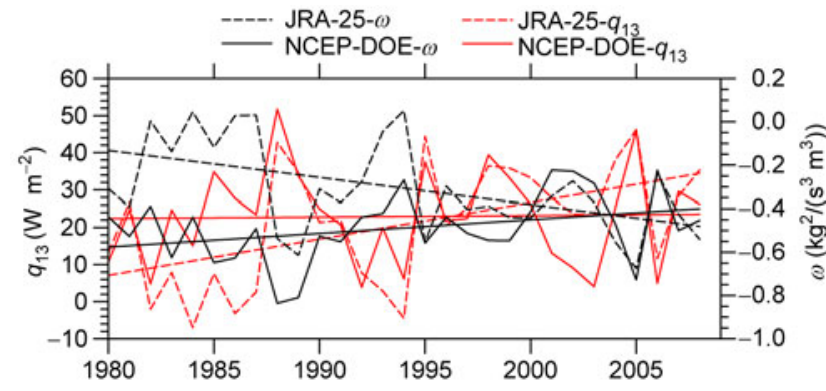

Figure 8 CE-TP temporal evolution of $q_{13}$ (red) and $\omega$ (black), computed from NCEP-DOE (solid) and JRA-25 (dash) data of 1980-2008.

mainly by the vertical velocity $\omega$. Correlation coefficients for NCEP/NCAR and JRA-25 were -0.96 and -0.84 , respectively. So the differences in $q_{13}$ of the two datasets may be attributed to their opposite trends in $\omega\left(0.06\left(\mathrm{~kg}^{2} /\left(\mathrm{s}^{3} \mathrm{~m}^{3}\right)\right) / 10 \mathrm{a}\right.$ for NCEP/NCAR and $-0.12\left(\mathrm{~kg}^{2} /\left(\mathrm{s}^{3} \mathrm{~m}^{3}\right)\right) / 10$ a for JRA-25). However, there were similarities between the annual changes in the two datasets, because the correlation coefficients between their $q_{13}$ and the corresponding $\omega$ were 0.62 and 0.36 . We also compared the time series of the 17-layer (1000$10 \mathrm{hPa}) \omega$ for the two datasets and found that there were similar trends only at $150,100,70$, and $50 \mathrm{hPa}$. The outstanding differences between $\omega$ of the datasets may be peculiar to the study region (TP). Consequently, we made analogous calculations for the East Asia region and found that the trends in the atmospheric heat source are similar, but very different in LVTs. The annual mean atmospheric heat source over the CE-TP from NCEP-DOE was distinctly higher than from the other datasets.

\section{Summary and discussion}

Using observations and reanalysis datasets, we have calculated trends in the atmospheric heat source over the CE-TP over the period 1980-2008. The main findings are summarized as follows:

(1) A significant decreasing trend occurred in SH over the last three decades. The linear tendency of 71-stationaveraged SH from 1980-2008 is $-3.9\left(\mathrm{~W} \mathrm{~m}^{-2}\right) / 10$ a. Surface wind speed contributed the most to long-term SH changes, and a continued weakening of winds led to a persistent reduction of SH over the CE-TP.

(2) $\left(T_{\mathrm{s}}-T_{\mathrm{a}}\right)$ greatly increased over the last 5 years, suggesting a pronounced warming of surface air temperature. This finding contrasts with that of Duan and Wu [18] for the period 1980-2003.

(3) A relatively weaker increase in $\mathrm{LH}\left(0.5\left(\mathrm{~W} \mathrm{~m}^{-2}\right) / 10 \mathrm{a}\right)$ from 1980-2008 was found. Using the ISCCP and SRB radiation data, we computed the $\mathrm{RC}$ over the $\mathrm{CE}-\mathrm{TP}$. There are very small differences between the annual means from the radiation datasets, but both suggest that the air column is a heat sink. The trends of the datasets for net shortwave, net long-wave and RC are very different and even contrary. Substantial differences between the two satellite radiation datasets suggest uncertainty in trend calculations for the TP atmospheric heat source.

(4) We have compared the heat source results based on the NCEP/NCAR, NCEP-DOE and JRA-25 reanalysis datasets and observations, generating the following findings. The trends $\left(-7.0\left(\mathrm{~W} \mathrm{~m}^{-2}\right) / 10 \mathrm{a}\right.$ and $\left.-2.5\left(\mathrm{~W} \mathrm{~m}^{-2}\right) / 10 \mathrm{a}\right)$ from the two NCEP datasets are close to OBS1 $\left(-12.1\left(\mathrm{~W} \mathrm{~m}^{-2}\right) / 10 \mathrm{a}\right)$ and OBS2 $\left(-3.7\left(\mathrm{~W} \mathrm{~m}^{-2}\right) / 10 \mathrm{a}\right)$, but JRA-25 shows a significant increase $\left(11.3\left(\mathrm{~W} \mathrm{~m}^{-2}\right) / 10 \mathrm{a}\right)$. Further analysis indicates that the main reason for this discrepancy are differences between the $\omega$ of JRA-25 and NCEP. Finally, NCEP-DOE produced the highest annual mean atmospheric heat source over the CE-TP.

It is very difficult to calculate accurately the atmospheric heat source for the TP. which has complex terrain and spare stations. Reanalysis data also possess great uncertainty, and different reanalysis datasets are discrepant. Although trends in the atmospheric heat source calculated by the two NCEP datasets are qualitatively consistent with observations, the magnitudes of changes are still very different, with NCEPDOE producing a much greater value. Therefore, for studies of trends in the atmospheric heat source over the TP, the choice of reanalysis datasets demands prudence.

The weakening trend in $\mathrm{SH}$ is associated with the spatial non-uniformity of global warming, i.e., greater warming at middle and high latitudes than over the tropics and subtropics. Recent climate warming primarily results from increasing anthropogenic greenhouse gas emissions, and impacts of those emissions on climate change in the plateau region are likely more serious than in the rest of the world [42]. The effect of heat changes over the TP on regional weather and climate may be investigated by a combination of observations and numerical simulation. Use of such simulation will be an increasingly important component of future studies. The dramatic increase in $\left(T_{\mathrm{s}}-T_{\mathrm{a}}\right)$ seen over the last 5 years may be related to changes in clouds. A reduction of total cloud amount produces an increase in shortwave radiation reaching the surface, and an increase in low cloud amount affects surface insulation. Together, they warm the surface rapidly. The relevant mechanisms need further study.

The authors are grateful to Prof. Guoxiong Wu for his helpful comments during the preparation and modification of the paper. Thanks are also extended to the anonymous reviewers for their constructive comments on an earlier manuscript. This work was supported by the Chinese Ministry of Science and Technology (2010CB951703 and 2009CB421403), the Knowledge Innovation Program of Chinese Academy of Sciences (KZCX2-YW-Q1101), and the National Natural Science Foundation of China (40975047).

1 Flohn H. Large-scale aspects of the summer monsoon in South and East Asia. J Meteor Soc Jpn, 1957, 35: 180-186

2 Flohn H. Recent investigations on the mechanism of the "summer monsoon" of southern and eastern Asia. In: Delhi N, ed. Monsoons of the World. India: Hindu Union Press, 1960. 75-88 
3 Ye D Z, Gao Y X, Zhou M Y, et al. Qinghai-Xizang Plateau meteorology (in Chinese). Beijing: Science Press, 1979. 278

4 Wu G X, Li W, Guo H, et al. Sensible heat driven air-pump over the Tibetan Plateau and its impacts on the Asian Summer Monsoon. In: Ye D Z, ed. Collections on the Memory of Zhao Jiuzhang. Beijing: Science Press, 1997. 116-126

5 Wu G X, Zhang Y S. Tibetan Plateau forcing and timing of the monsoon onset over South Asia and South China Sea. Mon Weather Rev, 1998, 126: 913-927

6 Tao S Y, Ding Y H. Observational evidence of the influence of the Qinghai-Xizang (Tibet) Plateau on the occurrence of heavy rain and severe convective storms in China. Bull Amer Meteor Soc, 1981, 62: 23-30

7 Duan A M, Wu G X. Role of the Tibetan Plateau thermal forcing in the summer climate patterns over subtropical Asia. Climate Dyn, 2005, 24: 793-807

8 Duan A M, Liu Y M, Wu G X. The sensible heat pattern over the Tibetan Plateau with the rainfall and circulation in eastern Asia in summer (in Chinese). Sci China Ser D-Earth Sci, 2003, 33: 997-1004

9 Zhao P, Chen L X. The climate characteristics of the atmospheric heat source over the Tibetan Plateau in past 35 years and its relationship with rainfall in China (in Chinese). Sci China Ser D-Earth Sci, 2001, 31: 327-332

10 Bai J Y, Xu X D, Zhou Y S, et al. Preliminary research on inhomogeneous distribution of Tibetan Plateau sensible heat fluxes in spring (in Chinese). J Appl Meteorol Sci, 2003, 14: 363-368

11 Duan A M, Wu G X. The main spatial heating patterns over the Tibetan Plateau in July and the corresponding distributions of circulation and precipitation over Eastern Asia (in Chinese). Acta Meteorol Sin, 2003, 61: 447-456

12 Liu X D, Chen B D. Climatic warming in the Tibetan Plateau during recent decades. Int J Climatol, 2000, 20: 1729-1742

13 Zhu W Q, Chen L X, Zhou Z J. Several characteristics of contemporary climate change in the Tibetan Plateau. Sci China Ser D-Earth Sci, 2001, 44: 411-420

14 Niu T, Chen L X, Zhou Z J. The characteristics of climate change over the Tibetan Plateau in the last 40 years and the detection of climatic jumps. Adv Atmos Sci, 2004, 21: 193-203

15 Zhou S W, Zhang R H. Decadal variations of temperature and geopotential height over the Tibetan Plateau and their relations with Tibetan Ozone depletion. Geophys Res Lett, 2005, 32: L18705

16 Luo H B, Yanai M. The large scale circulation and heat sources over Tibetan Plateau and surrounding areas during the early summer of 1979. Part II: Heat and moisture budgets. Mon Weather Rev, 1984, 112: 966-989

17 Chen L X, Reiter E R, Feng Z Q. The atmospheric heat source over the Tibetan Plateau: May-August 1979. Mon Weather Rev, 1985, 113 : 1771-1790

18 Duan A M, Wu G X. Weakening trend in the atmospheric heat source over the Tibetan Plateau during recent decades. Part I: Observations. J Climate, 2008, 21: 3149-3164

19 Yang K, Guo X F, Wu B Y. Recent trends in surface sensible heat flux on the Tibetan Plateau (in Chinese). Sci China Ser D-Earth Sci, 2010, 40: 923-932

20 Jian M Q, Luo H B, Qiao Y T. On the relationships between the summer rainfall in China and the atmospheric heat source over the eastern Tibetan Plateau and the Western Pacific warm pool (in Chinese). J Trop Meteorol, 2004, 20: 355-364

21 Lv Y Q, Gong Y F. Atmospheric heat source/sink change characteristics over Qinghai-Xizang Plateau and its vicinity region in summer of 2001 and 2003 (in Chinese). Plateau Meteorol, 2006, 25: 195-202

22 Zhao Y, Qian Y F. Relationships between the surface thermal anomalies in the Tibetan Plateau and the rainfall in the Jianghuai Aera in summer (in Chinese). Chin J Atmos Sci, 2007, 31: 145-154
23 Zhu Y X, Ding Y H, Xu H G. The decadal relationship between atmospheric heat source of winter and spring snow over Tibetan Plateau and rainfall in east China (in Chinese). Acta Meteorol Sin, 2007, 65: 946-958

24 Wang Y N, Zhang B, Chen L X, et al. Relationships between the atmospheric heat source over the Tibetan Plateau and the heat source and general circulation over East Asia. Chin Sci Bull, 2008, 53: 3387-3394

25 Qi D M, Li Y Q, L Y, et al. Variation of atmospheric heat source over east of the Tibetan Plateau in summer and its influence on climate of surrounding region (in Chinese). J Arid Meteorol, 2010, 28: 113-120

26 Zhao T B, Fu C B, Ke Z J, et al. Global atmospheric reanalysis datasets: current status and recent advances (in Chinese). Adv Earth Sci, 2010, 25: 242-254

27 Kanamitsu M, Ebisuzaki W, Woollen J, et al. NCEP/DOE AMIP-II Reanalysis (R-2). B Am Meteorol Soc, 2002, 83: 1631-1643

28 Zhao T B, Fu C B. Preliminary comparison and analysis between ERA-40, NCEP-2 reanalysis and observations over China (in Chinese). Clim Environ Res, 2006, 11: 14-32

29 Chen L X, Zhu Q G. East Asian Monsoon (in Chinese). Beijing: China Meteorological Press, 1991. 362

$30 \mathrm{Li} \mathrm{C} \mathrm{F}$, Yanai M. The onset and interannual variability of the Asian Summer Monsoon in relation to land-sea thermal contrast. J Clim, 1996, 9: 358-375

31 Li G P, Duan T Y, Wan J, et al. Determination of the Drag Coefficient over the Tibetan Plateau. Adv Atmos Sci, 1996, 13: 511-518

32 Li G P, Duan Y Y, Gong Y F. The bulk transfer coefficients and surface fluxes on the western Tibetan Plateau (in Chinese). Chin Sci Bull, 2000, 45: 865-869

33 Yanai M, Esbensen S, Chu J H. Determination of bulk properties of tropical cloud clusters from large-scale heat and moisture budget. J Atmos Sci, 1973, 30: 611-627

34 Yang K, Qin J, Guo X F, et al. Method development for estimating sensible heat flux over the Tibetan Plateau from CMA data. J Appl Meteorol Clim, 2009, 48: 2474-2486

35 Lu H L, Shao Q Q, Liu J Y, et al. Temporal-spatial distribution of summer precipitation over Qinghai-Tibet Plateau during the last 44 years (in Chinese). Acta Geogr Sin, 2007, 62: 946-958

36 Duan K Q, Yao S D, Wang N L, et al. The different in precipitation variability between the north and south Tibetan Plateau (in Chinese). J Glaciol Geocryol, 2008, 30: 726-732

37 Zhang J, Li D L. Evaluation and analysis of latent heat in rainy season in Qinghai-Xizang Plateau (in Chinese). Earth Sci Front, 2009, 16: $326-334$

38 Duan A M. The influence of thermal and mechanical forcing of Tibetan Plateau upon the climate patterns in East Asia (in Chinese). Dissertation for the Doctoral Degree. Beijing: Institute of Atmospheric Physics, Chinese Academy of Sciences, 2003. 1-161

39 Li Chuan, Zhang Y J, Chen J. Climatic change of Qinghai-Xizang Plateau region in recent 40-year reanalysis and surface observation data-contrast of observational data and NCEP, ECMWF surface air temperature and precipitation (in Chinese). Plateau Meteorol, 2004, 23: 97-103

40 Zhou S W, Zhang R H. Comparison of NCEP/NCAR reanalysis data and radiosonde data about temperature and geopotential height of upper air over the Tibetan Plateau (in Chinese). Clim Environ Res, 2009, 14: 284-292

41 Zhong S S, He J H, Guan Z Y, et al. Climatic characteristics of the atmospheric heat source over the Tibetan Plateau during 1961-2001 (in Chinese). Acta Meteorol Sin, 2009, 67: 407-416

42 Duan A M, Wu G X, Zhang Q, et al. New proofs of the recent climate warming over the Tibetan Plateau as a result of the increasing greenhouse gases emissions. Chin Sci Bull, 2006, 51: 1396-1400

Open Access This article is distributed under the terms of the Creative Commons Attribution License which permits any use, distribution, and reproduction in any medium, provided the original author(s) and source are credited. 